\title{
Triadic Gender Effect on the Susceptibility to Gender Bias and Ageism; and Its Subsequent Effect on Product Preference in C2C-Encounter
}

\author{
Sharayu S. Kirkole, Couchen Wu \\ Department of Business Administration, National Taiwan University of Science and Technology, Taiwan \\ Email: sharayu_ntust@yahoo.com
}

How to cite this paper: Kirkole, S.S. and Wu, C. (2017) Triadic Gender Effect on the Susceptibility to Gender Bias and Ageism; and Its Subsequent Effect on Product Preference in C2C-Encounter. Modern Econo$m y, 8,1414-1440$. https://doi.org/10.4236/me.2017.812095

Received: July 6, 2017

Accepted: December 5, 2017

Published: December 8, 2017

Copyright ( $) 2017$ by authors and Scientific Research Publishing Inc. This work is licensed under the Creative Commons Attribution International License (CC BY 4.0).

http://creativecommons.org/licenses/by/4.0/ (c) (i) Open Access

\begin{abstract}
This research proposes, the triadic gender effect (TGE) on gender based difference in consumer's susceptibility to social influence during the customer-to-customer (C2C) encounter and its subsequent influence on preferences for products perceived as being associated with the other consumer in buying context. It further investigates the role of ageism and gender bias on the stereotypic effect of the group category of the other consumer. We conduct two studies showing that, due to the gender differences in self-construal, information processing and social cognitive projection; men and women differ in the categorization and evaluation of groups based on gender and age. It further leads to the difference in the preference for the products perceived as being symbolically associated with the respective group members. In particular, women use a local approach, and draw more categories based on gender and age than men, who use a global approach and focus on larger groups. Additionally, women show a greater positive association with in-groups than do men; hence there is a more positive effect of in-group on women's product preference than on men's product preference. By contrast, men show a greater negative association with out-groups and dissociative groups than females; thus, there is a stronger negative effect of out-groups and dissociative groups on men's product preference. Overall women show greater positive association with groups than do men. The results show significant effect of gender bias and ageism in $\mathrm{C} 2 \mathrm{C}$ encounter.
\end{abstract}

\section{Keywords}

Consumer to Consumer-Encounter (C2C-Encounter), Triadic-Gender Effect, Gender Bias, Ageism, Categorization, Global/Local Processing Style Model (GLOMO) 


\section{Introduction}

Humans perform an automatic categorization of others into the basic primitive categories, like gender, age and race, and then develop stereotypes of these categories [1]. These categories are then utilized to classify and organize information that they receive from their environment [2] [3]. However, this complex phenomenon is oversimplified, especially in the marketing literature, by using gender and age as mere demographic descriptors. Previous research in this field has focused mainly on the consumer type and the dyadic relationship between consumer and brand [4], for studying the underlying primary factor, i.e., self-brand connection. However, for the first time, we study the unique triadic effect of gender.

In the buying environment, consumers often encounter other consumers who are buying some product, and they associate that product with that consumer. We term this spontaneous nonverbal automatic interaction as the $\mathrm{C} 2 \mathrm{C}$ encounter. This encounter leads to the automatic activation of stereotypes associated with the group to which the other consumer belongs. This stereotypic activation leads to the categorization of the consumer and further affects preferences for the product associated with that consumer in the $\mathrm{C} 2 \mathrm{C}$ encounter, which we term the automatic C2C encounter effect. We further study the gender-based differences in this stereotypic effect in terms of the categorization and evaluation of the consumer based on gender bias and ageism and the effect of the difference in the categorization and evaluation of the product symbolically associated with the consumer in the $\mathrm{C} 2 \mathrm{C}$ encounter. This gender effect comprises three gender-specific aspects, i.e., self-construal, information processing and social cognitive projection, which are responsible for gender-specific group categorization, evaluation and social behavior. We term this effect the "triadic gender effect" (TGE).

\section{Literature Review}

\subsection{The Customer-to-Customer (C2C) Encounter and the TGE on Social Categorization and Intergroup Behavior}

\subsubsection{The Role of Gender Schema}

A gender schema is a cognitively organized network of associations readily available to guide and provide standards for an individual's perceptions and gender-consistent behavior in a given scenario [5]. Gender schema theory states that men and women cognitively process and categorize new information in their environment according to their gender-based compatibility. Gender schema, thus influences the manner in which people attend, process, store, retrieve and use information [5]. The recent study by Montford and Goldsmith [6] has reported the gender difference in risk taking ability in case of investment decisions. Our research highlights the underlying psychological aspects in terms of the "TGE".

\subsubsection{Gender Bias and Intergroup Bias}

Intergroup bias refers to the systematic tendency to evaluate one's own mem- 
bership group i.e. in-group or its members, more favorably than that of a non-membership group i.e. out-group or its members [7]. This bias affects behavior (discrimination), attitude (prejudice), as well as cognition (stereotyping) [8] [9]. It results in in-group favoritism and out-group derogation [10] [11] [12]. A person's self-image or mental model of self-comprises the self-conception, qualities, beliefs and expressions that conform with his or her gender; it is the degree to which one views oneself as a person and a group member [13]. Thus, we suggest that, as women consider themselves to be members of the female group (in-group), they will consider men to be the out-group, and vice versa.

\subsubsection{Ageism-Dissociative Group Categorization}

Dissociative groups are the groups, people avoid association and "disidentify" with it [14] [15]. These are the undesired selves, one wish to avoid [16] [17] and disparages [18] [19]. Thus projects avoidance renunciation towards these groups [20]. By contrast, individuals show less-negative stereotypes towards out-groups and these stereotypes are associated with a sense of difference, opposition or derogation. The out-group can be viewed negatively, such as in the case of the opposite group, e.g., gender, or positively, such as in the case of an aspirant group or a warm group, e.g., models for girls and athletes for boys. However, the dissociative group is significantly distinct from and more negatively perceived than the out-group [20].

\subsubsection{Stereotypes Associated with Ageism}

Ageism is defined as discrimination against the elderly and seniors, comprising three interconnected elements: prejudice against elderly people, elderly age and the aging process; discrimination against elderly people; and institutional practices and policies that maintain stereotypes of elderly people [21] [22].

Many studies have reported an automatic, strong and negative influence of ageism; specifically, Perdue and Gurtman [23], reported that the participants primed with traits of elderly persons recalled more negative traits of elderly persons than other participants who were primed with traits of younger persons. Hence, considering the intensity of the negative effect of age groups, we define the group of elderly, which is perceived more negatively than the out-group (that is opposite gender), as the dissociative group. Hence, we propose that-

H1: Men and women will show more positive association with the gender in-group than with the gender out-group.

$\mathrm{H} 2$ : Men and women will show stronger negative association with the dissociative group than with the out-group.

\subsubsection{The Role of Self-Construal}

\section{a) Self-construal}

Past cross-cultural studies revealed that individuals' social aspects of self may influence their self-representations, like membership in social groups [24] [25] [26]. Based on their self-concept, people pay attention to and remember the domain-specific information of the self and others but ignore or resist do- 
main-inconsistent information [27] [28] [29].

b) Gender difference in self-construal

According to Cross \& Madson [30], differences in the gender-based self-stereotyping process between men and women lead to differences in their self-construals [31]-[36]. Especially, women possess higher relational interdependence and men possess higher independence [30]-[41], which affects their cognition, motivation, emotion, psychological processes and social behavior [30] [37] [39] [42] [43].

\section{c) Men-Independent self-construal}

According to Markus \& Kitayama [25], in case of independent self-construal, the mental representations of others are separate from the mental representation of the self. These individuals aim to maintain autonomy; they tend to be true to their internal structure of preferences, convictions, goals and rights [44], and satisfying these goals enhances their self-esteem. Their thoughts and actions focus on highlighting their uniqueness, and they try to stand out from others [25] [45]. Thus, in the case of independent self-construal, relationships with others serve as a reflection of the individual's comparison of the self with others, and dominance over others is the aim [46] [47] [48]. Thus, men with independent self-construal focus on self-determination and differentiation [49] [50].

d) Women-Interdependent self-construal

Women tend to construct and maintain an interdependent self-construal, i.e., "connectedness with others"; hence, the boundaries between self and others are open. People with interdependent self-construal pay more attention to the information about relationships and they encode and organize the information in terms of relationships [30] [51], as their aim is to maintain relationships [49] [50]. In their experiment, Clancy \& Dollinger [52] found that women were more likely than men to select pictures of themselves with family members or others, whereas men select pictures of themselves alone. Women follow an assimilation process during interpersonal interactions, which leads to more positive interpersonal interactions than those experienced by men, who use a contrast process in interpersonal interactions [53]. Hence, we propose that men, being "self-contained autonomous entities", will show weaker association with group than women with relational self.

\subsubsection{Gender Differences in Information Processing during Categorization (Item-Specific versus Relational)}

Previous studies have reported that men pay attention to the gross and key attributes that have the greatest personal impact, whereas women evaluate several attributes to determine the interrelationships among them [54] [55] [56]. Past research reported that, in the same task context, women process information more comprehensively than men [57] [58] [59] [60] [61]. Recent studies have reported that women possess more stereotype knowledge than do men [62] [63] [64] and draw a greater number of gender stereotypes than men [65].

Women tend to use all dimensions of stereotypic cues during categorization; 
hence, they perform a systematic categorization of others [25] [54] [55] [56] [65]. Studies in the advertising field suggest that men focus on the direct message given in an advertisement, i.e., item-specific processing, such as "buy this beer", whereas women not only consider the primary message but also pay attention to multiple clues from the message and use them to intuit and infer its inner meaning, i.e., relational processing, e.g., buy this beer to become popular and trendy [66]. According to these studies, men use linear thinking and reasoning in a decision making process and have a more task-oriented focus than women, whereas women process information from many levels and sources, e.g., advertisement-related elements such as music, voice-overs, visuals, text, etc. and evaluate and measure various sources to decide their next steps. In contrast to that of men, women's decision-making process is an incremental reasoning process in which they build each piece of information on top of the previous information; thus, they consider interrelated factors and not simply straight lines as they evaluate multiple sources [67]. Women are more visually and intrinsically oriented [68] and more sensitive to situation-specific cues than men, whereas men are found to be detached [69]. Women follow relational processing and perform a systematic categorization of others than men who follow item-specific processing [25] [54] [55] [56].

The explanation of the above phenomenon is explained in more details by "the Global versus Local processing model" (GLOMO) [70], which states that approach and avoidance are the two basic motivational orientations that influence people's cognitive and perceptive processes. The approach orientation leads to global processing that focuses on larger units (e.g., a door as part of a house or a tree as a part of jungle), and the avoidance orientation leads to local processing that focuses on smaller units (e.g., the door or the tree as a unit or isolated object) [70] [71] [72] [73] [74]. Specifically, independent self-construal of men follows an approach strategy, whereas interdependent self-construal of women follows avoidance-oriented strategy [72] [75] [76].

Hence, we predict that women will draw more categories based on the age and gender-specific cues of groups than will men, whereas, men who possess independent self-construal and an approach orientation, will follow global processing and endorse large groups, i.e., age groups (young vs. old) more distinctively than sub-groups i.e. gender groups, within age groups; whereas, women, who have interdependent self-construal and an avoidance orientation, will follow local processing and, thus endorse all four categories distinctively (i.e., girl, boy, elderly women, and elderly men).

H3a: Women will distinguish all the four types of groups distinctively including the age groups and the gender groups within each age group.

H3b: Men will distinguish larger groups, i.e., the age groups distinctively but not the gender groups within each age group.

\subsubsection{The Role of Social Projection}

Social projection is termed as the tendency to expect similarities between oneself 
and others [77]. According to the literature review and the meta-analysis conducted by Robbins and Krueger, people have stronger social projection, when they make judgments about in-groups than that about out-groups, which results into in-group favoritism and perceived in-group homogeneity as well as intergroup discrimination [77]. This research has further studied this phenomenon in case of gender based categorization.

a) Gender orientation: Men with an agentic orientation and women with a communion orientation

Differences in gender orientation result into differences in social projection and identification with groups [37] [78]. According to Arndt et al. [79], social projection is stronger for people with a need for social connectedness. According to Fiske et al. [80] and Fiske \& Cuddy [81], gender stereotypes are scalar structures along the two complementary dimensions, i.e., agency (competence) and communion (warmth), in which men's sense of worth is associated with autonomy and a sense of personal accomplishment that is agency orientation, whereas women's sense of belongingness is associated with connectedness and sensitivity to others i.e., communion orientation [82] [83] [84] [85] [86]. Women thus follow assimilation process during interpersonal interaction, which leads to greater positive interpersonal interaction than men, who use contrast process in interpersonal interaction [53].

b) In-group identification and evaluation

In-group identification is the extent to which individuals consider themselves to be group members [87]. It is observed that self-construal and the degree of identification with the in-group vary with gender [30] [37] [40]. In their two experiments, Rudman and Goodwin [88] found that men and women both have a strong identification with their gender and show strong self-esteem, while women show significantly greater in-group bias than men.

Men, with independent-self and agentic-orientation, strive for domination and possess a sense of separateness from others, whereas women, with a communion orientation, strive for contact and congregation to maintain social bonds and, hence, desire to connect with others [53] [89], which further leads to stronger in-group bias. By contrast, men, who have high levels of self-esteem, demonstrate weak in-group bias [90] [91]. Thus, we propose that women, who have a need for social connectedness, will be more likely to conform and to have a greater positive association with the in-group than men, who will likely prefer being separate from others.

H4: Women will categorize the in-group more positively than will men.

c) Out-group and dissociative group identification and evaluation

According to the theory of gendered prejudice McDonald [92], men's prejudice can be defined by aggression and dominance over groups, whereas women's prejudice can be defined by wariness and fearfulness of out-groups, mainly with regard to men as their out-group. Further, Locke, K.D. \& Nekich, J.C. [93] found that, in social comparisons, agentic traits such as dominant, competitive, and ambitious lead individuals to focus on dissimilarities and downward compari- 
sons and strive for expansion and elevation [89], leading to feelings of confidence and the satisfaction of their desire for dominance and competence. Hence, we propose that the urge to be unique, dominated and separate from others will lead men to use contrast strategy and will follow downward comparison to create distance from out group as well as dissociative group i.e. they will show stronger negative association with out-group than women, who tend to exhibit communion traits such as warmth, sympathy and tenderness [93] and who strive for contact, congregation and the maintenance of social bonds through assimilation [89].

Thus, in the case of men possessing independent self-construal, comparison with the out-group leads to an elevated need to differentiate from the out-group in order to create a unique self-concept and contrast that satisfies their strong self-differentiation goal. By contrast, in the case of women, the interdependent self-construal makes them more immune to the out-group and dissociative because their primary goal is to conform to the in-group to satisfy their relationship goals [50]. Hence, we propose-

H5: Men will show stronger negative association with the out-group and the dissociative group than will women.

\subsection{C2C Encounter Effect and TGE on Product Preference: The Role of Gender Bias and Ageism}

A plethora of research in the marketing field suggests that the type of reference group influences the products or brands associated with it. Many previous studies have reported congruency between reference group membership and brand usage, e.g., [94] [95] [96] [97].

This research has investigated the nonverbal, spontaneous C2C encounter effect on product preference, by creating a scenario of lucky draw winners among early buyers. Previous studies have focused mainly on the domain of reference groups in terms of nationality, race or other dimensions of social discrimination, but these types of encounters are not as common and obvious as encounter with gender or age groups. Hence, we take the initiative to investigate this very basic and universal tendency toward gender bias and ageism.

Recent research suggests that consumers construct their self-identity and present themselves to others through their brand choices that are based on the congruency between brand-user associations and self-image associations [98]. Belk, R.W. [99] and Richins [100] reported that people engage in consumption behavior to some extent to construct their self-concepts and personal identity. Further, Escalas, J.E. \& Bettman, J.R. [101] found that, for nationality-based reference groups, the self-brand connection was stronger for brands consistent with the in-group than for those consistent with the out-group. Previous studies have reported the positive influence of positive membership and the aspirational reference group on individuals' intention, attitudes and behaviors [14] [87] [102], exercise intentions [103], intentions to engage in sun-protective behaviors [103], evaluations of products and advertisements [102], product and brand selections 
[94] [104], information seeking and purchasing decisions [105], brand usage [94] [95] [96] [97], and purchase intentions [106].

Hence, we propose that, in a $\mathrm{C} 2 \mathrm{C}$ encounter, the positive association with in-group will lead to a stronger positive effect on the preference for products associated with in-group than for the products associated with out-group.

H6: The C2C encounter with an in-group member will have a stronger positive effect on the preference for products perceived as purchased by the in-group than for those purchased by the out-group.

Past studies have reported that consumers avoid products that have negative symbolic implications [107] and represent negative attitudes towards lifestyles that they wish to avoid [108], and they demonstrate their selves by avoiding products associated with these groups [109]. Further, White and Argo [110], reported that the desire to avoid dissociative reference groups creates negative influence on consumer preferences. Hence, we propose the following:

H7: The C2C encounter with a dissociative group member will lead to a stronger negative effect on the preference for products perceived as purchased by the dissociative group than for those perceived as purchased by the in-group and the out-group.

Further, we propose that the gender effect in categorization, as discussed in part 1, will lead to difference in the intensity of the group effect in the $\mathrm{C} 2 \mathrm{C}$ encounter. As women endorse all four group categories distinctively ( $\mathrm{H} 1)$, they will show a significant difference in the stereotypic C2C-encounter effect on preference for the all four product types based on type of group associated with respective product. Hence, we propose the following-

H8a: In a C2C encounter, women will show significant difference in the preference for the products perceived as being purchased by the respective members of group categories based on age and gender.

H8b: In a C2C encounter, men will show a significant difference in the preference for the products perceived as being purchased by the group categories based on age but not for the sub-groups based on gender within the age groups.

Because women have a greater positive association with the in-group than do men (H1), women will show greater positive influence of in-group on product preference than will men. We propose-

H9a: In a C2C encounter, the in-group will have a stronger positive effect on women's preference for products perceived as being purchased by in-group members than on men's preference.

Consumers with independent self-construal have a stronger negative perception of brands with images that are consistent with the out-group than do those with interdependent self-construal [38] [62].

Hence, we propose that, as men possess independent self and have stronger negative orientation towards negative groups and as women possess interdependent self and are immune to negative groups; in case of $\mathrm{C} 2 \mathrm{C}$ encounter with out-group and dissociative groups, men will show stronger negative influence on the preference for products associated the respective groups than will women. 
H9b: In a $C 2 C$ encounter, there will be a stronger negative impact of the out-group and dissociative group on men's preference for products perceived as being purchased by the respective groups than on women's preference.

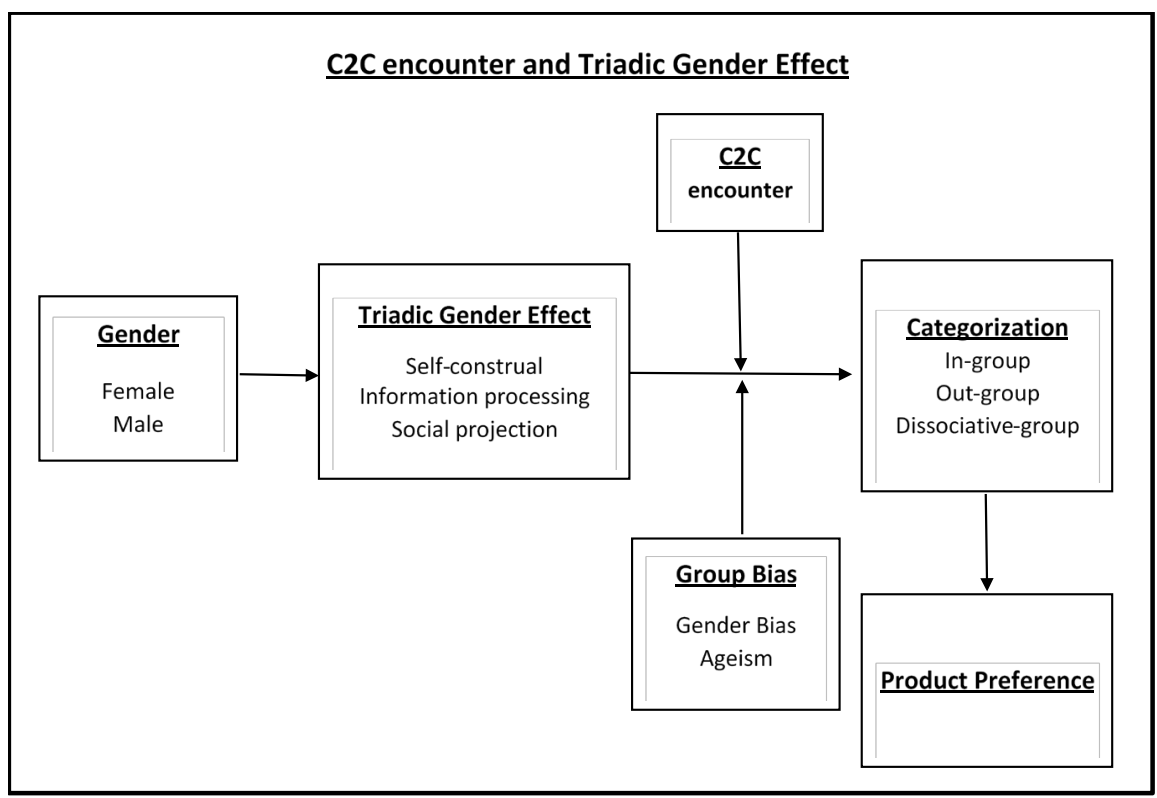

\section{Experiment Design}

To avoid interpersonal interactions, we conducted the induction and the study in separate rooms. Seats were arranged in such a way that the participants would not be able to see each other. The message "keep silence" was displayed outside both rooms, and the participants were asked to keep their cell phones muted. In the induction hall, we gave instructions to the participants regarding the procedure and tasks. They were told that we were a research laboratory and that we intended to conduct a few unrelated studies for our various clients (based on the task to be performed; the client list was modified for experiments 1 and 2). The common instructions included the following: A social research company wants to study the personality traits of people similar to you; a game company wants to study how people similar to you react to different puzzles; an event management company wants to know the opinions of people similar to you about different types of people they come across in the social environment; and a psychological research institute wants to study memory decay over time for people who are similar to you. In this final scenario, in order to ensure a sufficient cognitive load, participants underwent a memory task in which they were shown a 7 alphabets' non word before they left the induction room headed for the study room. They had to remember this code word throughout the entire session. They were told that, because this is a psychological task, they should not interact with each other in the entire session, because doing so will affect memory decay. After the induction, the students went to the study room one by one. To make the prior activations disappear, they were told to begin the study session only af- 
ter they heard a buzzer. After all of the students entered the study room, our representative, sitting in the study hall and pretending to be a participant, was informed of the time by receiving a missed call on her/his cellphone, which was kept on vibrate. Then, the representative pressed the buzzer after a short delay. After the students finished the task, they were asked to fill up personal information which included the demographic information, purpose of the study and code word. Then, they were debriefed and were told the actual purpose of the study. Then they were given complimentary gifts for their participation.

\subsection{Selection of Symbolic Products}

Previous research suggests that symbolic products, unlike utilitarian products, are products that consumers consume mostly for sensory gratification or affective purposes [3] or hedonic purposes, such as looking good [3] [71]. According to [38], the interpersonal influence on consumer behavior is greater for symbolic brands than it is for non-symbolic brands. Hence, to retrieve the subconscious stereotyping process, we selected symbolic product, an aroma-body soap, which is associated with the hedonic values of beauty and pleasantness. We created a fake body-soap brand, "Alsoft", with a series of four types labeled as volume 1, 2, 3 , and 4 with similar chemical composition in the column of ingredients and a special ingredient in the title which was different for all four body soaps. We mimicked this from the current trend in aroma body soap brands.

\subsection{Manipulation of Groups}

The four group categories were introduced by using photographs of ordinary persons of different gender and age groups, i.e., girls and boys who belong to the age group of the participants but represent the in-group (same gender) and the out-group (opposite gender), and elderly women and elderly men, who represent the dissociative-group (to test the significance of the effect of gender within the dissociative group, we used both genders under this age group). To facilitate the $\mathrm{C} 2 \mathrm{C}$ encounter in experiment 2, during the induction, we noted that, while launching a new series of body soaps in one trade exhibition, Alsoft announced lucky draws among the first 50 buyers, and the lucky winner was offered a gift package; additionally, under treatment condition, we placed photographs of the member of each group category with a note, "lucky draw winner", next to the photograph of each product on each product information leaflet, where as in control condition the photograph of member of group category and the note of lucky winner was absent.

\subsection{Measure of Group Categorization}

A 3-item, 6-point Likert scale for group categorization was used. The participants rated the three items, e.g., "I consider myself to be this type of person" and "I belong to this group", on a scale ranging from $1=$ strongly disagree to $6=$ strongly agree [38]. 


\subsection{Pretest-1-Categorization of Groups}

A total of 28 students ( 16 females and 12 males) participated in the test; they evaluated each photograph of the group members i.e. girl, boy, elderly woman (EW), elderly man (EM) on the group categorization scale ranging from $1=$ not at all preferred to $6=$ the most preferred. The one-way repeated measures ANOVA conducted to compare the difference in the categorization of the four groups. A repeated measures ANOVA with a Greenhouse-Geisser correction determined that the mean of group categorization differed statistically significantly between four group conditions $(\mathrm{F}(1.904,51.418)=56.511, \mathrm{p}<0.001)$. Post hoc tests using the Bonferroni correction revealed that there was statistically significant difference in categorization of all four groups. The participants, successfully categorized same gender and young age group as in-group (in-grp), young age-group and opposite gender as out-group (out-grp) and elderly people of both gender as dissociative group (disso-EW and disso-EM). [ $\left(\mathrm{M}_{\mathrm{in}-\mathrm{grp}}=4.131\right.$, $\mathrm{SD}=0.170)$ vs $\left.\left(\mathrm{M}_{\text {out-grp }}=3.440, \mathrm{SD}=0.140\right) ; \mathrm{p}<0.001\right] ;\left[\left(\mathrm{M}_{\text {out-grp }}=3.440, \mathrm{SD}=\right.\right.$ $0.140)$ vs $\left(\mathrm{M}_{\text {disso-EW }}=2.619, \mathrm{SD}=0.124 ; \mathrm{p}<0.001\right]$; and $\left[\left(\mathrm{M}_{\text {disso-EW }}=2.619, \mathrm{SD}=\right.\right.$ $0.124)$ vs $\left.\left(\mathrm{M}_{\text {disso-EM }}=2.107, \mathrm{SD}=0.100\right) ; \mathrm{p}<0.001\right]$. Thus the manipulation of group categories was successful. The reliability statistics for the 3-item group categorization scale was significant (Cronbach's Alpha $=0.834$ ).

\subsection{Pretest-2-Product Type}

A total of 22 graduate students (10 females and 12 males) participated in the pretest, giving their preference for the 4 types of Alsoft aroma body soap on a six-point Likert scale ranging from $1=$ not at all preferred to $6=$ the most preferred.

A repeated measures ANOVA was conducted to compare difference in preference for the four product types. Mauchly's test of sphericity conducted for product type, indicated that the assumption of sphericity is not violated, $\left(\chi^{2}(5)=\right.$ $1.320, p>0.9)$ and the sphericity assumed results showed no significant difference in preference for the four Alsoft body soap types $(\mathrm{F}(3,63)=0.547, \mathrm{p}>0.6)$. Most importantly, the average response for all four body soaps was medium $\mathrm{M}_{\mathrm{vol}-1}=3.50, \mathrm{M}_{\mathrm{vol}-2}=3.18, \mathrm{M}_{\mathrm{vol}-3}=3.09, \mathrm{M}_{\mathrm{vol}-4}=3.36$, which was necessary to elicit the treatment effect.

\subsection{Experiment-1: TGE in Social Categorization and Stereotyping - Gender Bias and Ageism}

\subsubsection{Purpose}

The purpose of this study is to identify TGE on categorization of groups based on gender and age.

\subsubsection{Method}

A total of 53 graduate students ( 23 females and 30 males, average age $=24$ yrs.) participated in this study. We followed the procedure as explained in the experiment design. In the study session, the participants first completed the group 
categorization questionnaire, which contained 4 photographs of faces of a girl, a boy, an elderly woman and an elderly man, each followed by the 3-item, 6-point Likert scale for group categorization. After completion of the questionnaire, they filled out the demographic questionnaire.

After they finished the task, they were debriefed and were told the actual purpose of the tasks and were given gifts. Then they were given gifts for the participation.

\subsubsection{Analysis and Results}

A 2 (gender: female vs. male) $\times 4$ (group category: girl, boy, elderly woman (EW), elderly man (EM) mixed design was used, where group category was within-subject variable and group categorization was the dependent variable. A mixed repeated measures ANOVA with a Greenhouse-Geisser correction determined that the mean of group categorization differed statistically significantly between four group conditions $(\mathrm{F}(2.567,130.906)=112.601, \mathrm{p}<0.001)$. There was significant interaction between the group category and gender ( $\mathrm{F}$ (2.567, $130.906)=4.396, \mathrm{p}<0.007)$. The Post Hoc using Turkey correction revealed significant effect of gender on categorization $(F(1,51)=39.008, p<0.001)$. Further, the post hoc tests using the Bonferroni correction revealed that there was statistically significant difference in categorization of all four groups, $\left(\mathrm{M}_{\text {in-grp }}=\right.$ 3.990 vs $\mathrm{M}_{\text {out-grp }}=3.456 ; \mathrm{p}<0.001 ;\left(\mathrm{M}_{\text {out-grp }}=3.456\right.$ vs $\mathrm{M}_{\text {disso-EW }}=2.397 ; \mathrm{p}<$ 0.001 ; and $\left(\mathrm{M}_{\text {disso-EW }}=2.397\right.$ vs $\left.\mathrm{M}_{\text {disso-EM }}=1.962 ; \mathrm{p}<0.002\right)$, supporting $\mathrm{H} 1$ and $\mathrm{H} 2$.

To understand the details of the gender effect, we separately conducted a repeated measures ANOVA for the data of the male and female respondents.

The Mauchly's test of sphericity, in case of female participants, indicated that the assumption of sphericityis not violated, $\chi^{2}(5)=6.724, p>0.2$ and the sphericity assumed results showed significant effect of group category, $(F(3,66)=$ 55.273, $\mathrm{p}<0.001$. Further, post hoc tests using the Bonferroni correction revealed that there was statistically significant difference in categorization of all four groups, $\left(\mathrm{M}_{\text {Fin-grp }}=4.536\right.$ vs $\mathrm{M}_{\text {F-out-grp }}=3.812 ; \mathrm{p}<0.02 ;\left(\mathrm{M}_{\text {F-out-grp }}=3.812\right.$ vs $\mathrm{M}_{\mathrm{F}-\text { disso-EW }}=2.739 ; \mathrm{p}<0.002 ;$ and $\left(\mathrm{M}_{\mathrm{F}-\text { disso-EW }}=2.739\right.$ vs $\mathrm{M}_{\mathrm{F}-\text { disso-EM }}=2.058 ; \mathrm{p}<$ 0.007), which supported H3a.

In case of male participants, a repeated measures ANOVA with a Greenhouse-Geisser correction determined that the mean of group categorization differed statistically significantly between four group conditions (F $(2.327,67.497)$ $=55.038, \mathrm{P}<0.001)$. Post hoc tests using the Bonferroni correction revealed that there was statistically significant difference in categorization of age groups but as predicted, the categorization of gender groups within age group was not significant, $\left(\mathrm{M}_{\mathrm{M} \text {-in-grp }}=3.444\right.$ vs $\left.\mathrm{M}_{\mathrm{M} \text {-out-gr } \mathrm{p}}=3.100 ; \mathrm{p}>0.09\right) ;\left(\mathrm{M}_{\mathrm{M} \text {-out-grp }}=3.100\right.$ vs $\left.\mathrm{M}_{\mathrm{M} \text {-disso-EW }}=2.056 ; \mathrm{p}<0.001\right)$; and $\left(\mathrm{M}_{\mathrm{M} \text {-disso-EW }}=2.056\right.$ vs $\left(\mathrm{M}_{\mathrm{M} \text {-disso-EM }}=1.867 ; \mathrm{p}>\right.$ 0.7), which supported H3b.

Paired comparison T-tests were conducted to compare means for group categorization for understanding gender difference in the strength group categoriza- 
tion. There was significant gender difference in the scores for categorization of in-group, where female categorized in-group more positively than men, $\left(\mathrm{M}_{\mathrm{F} \text {-in-grp }}\right.$ $=4.536, \mathrm{SD}=0.584)$ and $\left(\mathrm{M}_{\mathrm{M} \text {-in-grp }}=3.391, \mathrm{SD}=0.833\right), \mathrm{t}(22)=5.797, \mathrm{p}<0.001$; which supported $\mathrm{H} 4$. The gender difference in categorization of out-group was significant and as predicted men categorized out-group more negatively than women, $\left(\mathrm{M}_{\mathrm{F}-\text { out-grp }}=3.812, \mathrm{SD}=0.815\right)$ and $\left(\mathrm{M}_{\mathrm{M} \text {-out-grp }}=3.072, \mathrm{SD}=0.689\right) ; \mathrm{t}$ (22) $=3.143, \mathrm{p}<0.006$; which supported H5. The gender difference in categorization of dissociative -group was significant and as predicted men categorized elderly women and elderly men more negatively than women, $\left(\mathrm{M}_{\mathrm{F}-\text { disso-EW }}=2.739, \mathrm{SD}=\right.$ $0.847)$ and $\left(\mathrm{M}_{\mathrm{M} \text {-disso-EW }}=2.014, \mathrm{SD}=0.455\right) ; \mathrm{t}(22)=3.715, \mathrm{p}<0.002$, which supports $\mathrm{H} 5$; but the gender difference in categorization of dissociative groups was marginally significant, $\left(\mathrm{M}_{\mathrm{F}-\text { disso-EW }}=2.057, \mathrm{SD}=0.802\right)$ and $\left(\mathrm{M}_{\mathrm{M} \text {-disso- } \mathrm{EM}}=1.855\right.$, $\mathrm{SD}=0.436) ; \mathrm{t}(22)=1.064, \mathrm{p}>0.2$. Thus, in total, results of categorization supported $\mathrm{H} 5$.

\subsubsection{Discussion}

Overall, the results show that women endorse more categories from the same set of groups than do men and significantly differentiate them into the categories based on age and gender within each age group. By contrast, men group the four categories into two significantly different larger groups, i.e., age groups, and the difference between the sub-groups based on gender within each age group was not significantly different. Further, the T-tests revealed that women had a stronger positive association with the in-group, than did men; additionally, men showed a stronger negative association with the out-group and the dissociative than did women, except in the case of the elderly men, where the gender difference was marginally significant. Overall, women showed more positive association with gender and age based categories than did men.

\subsection{Experiment-2: TGE in the C2C Encounter on Product Preference and the Role of Group Categorization in the Process}

\subsubsection{Purpose}

The purpose of the experiment is to study, how gender affects the categorization of groups and how this categorization further affects people's preference for products that are perceived as being bought by the respective group member.

\subsubsection{Method}

The procedure in the second experiment closely followed the procedure described in the experimental design, except for one addition to the induction session: we told the participants that our client, "Alsoft" body soap, wanted to determine the preferences of people similar to them for the company's recently launched series of aroma body soaps.

A total of 107 graduate students ( 53 females and 54 males, average age $=24.5$ yrs.), participated in the study. They were randomly assigned to the control versus treatment condition. We used a mixed design in which the four types of 
body soaps in the control condition and the 4 types of groups with the product type in the treatment condition adopted a within-subjects design. The sample group was randomly divided into the control and the treatment conditions, some filler tasks were introduced between each questionnaire which included filler questionnaires and puzzles. After they finished the 4 sets, the participants completed the group categorization questionnaire, followed by the demographic questionnaire. After they finished this final task, they were debriefed and were told the actual purpose of the study. At the end of the session, they received gifts.

\subsubsection{Analysis and Results}

\section{a) Control condition-product preference}

A 2 (gender: female vs. male) $\times 4$ (type of body soap: vol-1, vol-2, vol-3, vol-4) mixed design was used where the type of body soap condition was between-subjects and product preference was the dependent variable. A total of 51 graduate students (26 females and 25 males) underwent control condition on random basis.

A mixed repeated measures ANOVA was conducted to study the effect of gender and body soap type on product preference. The Mauchly's test of sphericity in the control condition indicated that the assumption of sphericityis not violated, $\chi^{2}(5)=7.856, \mathrm{p}>0.1$ and the sphericity assumed results showed that there was no significant effect of body soap type, $(F(3,147)=0.899, p>0.4)$. There was no significant effect of gender on product preference $(F(1,49)=$ $2.768, \mathrm{p}>0.05)$. The average preference for each body soap time was medium $\left(\mathrm{M}_{\mathrm{vol}-1}=3.802, \mathrm{M}_{\mathrm{vol}-2}=3.895, \mathrm{M}_{\mathrm{vol}-3}=3.761\right.$ and $\mathrm{M}_{\mathrm{vol}-4}=3.663$.

b) Treatment condition-product preference

A 2 (gender: female vs. male) $\times 4$ (group types: girl, boy, elderly women, elderly men) mixed design was used, with group type as a between-subject variable and product preference as a dependent variable. A total of 56 graduate students (27 females and 29 males) underwent treatment condition. A mixed repeated measures ANOVA using Greenhouse-Geisser correction determined that the product preference differed statistically significantly between the four group conditions $(\mathrm{F}(2.330,125.827)=67.979, \mathrm{p}<0.001)$. It also revealed, significant effect of gender on product preference, $(\mathrm{F}(1,54)=10.672, \mathrm{p}<0.003)$. Post hoc tests using the Bonferroni correction revealed statistically significant difference in product preference for all four group categories. The in-group had a stronger positive effect on product preference than did the out-group $\left(\mathrm{M}_{\mathrm{in}-\mathrm{grp}}=4.516 \mathrm{vs}\right.$ $\mathrm{M}_{\text {out-grp }}=3.549 ; \mathrm{p}<0.001$ ). This supports H6. By contrast, the dissociative group had a more negative effect than did the out-group on product preference $\left(\mathrm{M}_{\text {out-grp }}\right.$ $=3.549$ vs $\mathrm{M}_{\text {disso-EW }}=2.855 ; \mathrm{p}<0.001$; and $\left(\mathrm{M}_{\text {disso-EW }}=2.855\right.$ vs $\mathrm{M}_{\text {disso-EM }}=2.236$; $\mathrm{p}<0.001$ ), which supports $\mathrm{H} 7$.

To understand gender difference, separate analyses on the male and female respondents was conducted using a repeated measures ANOVA and a T-tests.

The Mauchly's test of sphericity conducted for female participants, indicated that the assumption of sphericity is not violated, $\chi^{2}(5)=10.201, p>0.07$ and the 
sphericity assumed results showed that there was significant effect of group category on product preference, $(\mathrm{F}(3,78)=43.322, \mathrm{p}<0.001)$.

Post hoc tests using the Bonferroni correction revealed that there was statistically significant difference of all four group categories on the product preference, $\left(\mathrm{M}_{\text {in-grp }}=4.963\right.$ vs $\mathrm{M}_{\text {out-grp }}=3.926 ; \mathrm{p}<0.02 ;\left(\mathrm{M}_{\text {out-grp }}=3.926\right.$ vs $\mathrm{M}_{\text {disso-EW }}=3.296 ; \mathrm{p}$ $<0.02$; and $\left(\mathrm{M}_{\text {disso-EW }}=3.296\right.$ vs $\left.\mathrm{M}_{\text {disso-EM }}=2.333 ; \mathrm{p}<0.001\right)$, which further supported H8a.

In case of male participants, the repeated ANOVA for the two age group categories (i.e. young-age group vs old-age group) was conducted. The result showed significant difference in the effect of age group on product preference [Pillai's Trace; 0.514, F $(1,57)=60.332, \mathrm{p}<0.001]$. Further, the post hoc test using the Bonferroni correction revealed statistically significant difference in product preference in case of age group categories $\left(\mathrm{M}_{\mathrm{M} \text {-young-age-grp }}=3.621\right.$ vs $\mathrm{M}_{\mathrm{M} \text {-old-age-grp }}=2.276 ; \mathrm{p}<0.001$ ), which supports H8b.

The repeated ANOVA for the subgroups was also conducted for all four group categories. The Mauchly's test of sphericity conducted for the subgroups indicated that the assumption of sphericity is violated, $\chi^{2}(5)=18.036, p<0.003$. Further, Greenhouse-Geisser correction determined significant effect of group categories on product preference $(\mathrm{F}(2.164,60.581)=26.735, \mathrm{p}<0.001)$. Post hoc tests using the Bonferroni correction revealed statistically significant difference in product preference in case of larger groups i.e. age group categories (young vs old) $\left(\mathrm{M}_{\text {out-grp }}=3.172\right.$ vs $\mathrm{M}_{\text {disso-EW }}=2.414 ; \mathrm{p}<0.02$. By contrast, the difference in product preference, in case of the subgroups within each age group was not significant $\left(\mathrm{M}_{\text {in-grp }}=4.069\right.$ vs $\left.\mathrm{M}_{\text {out-grp }}=3.172 ; \mathrm{p}>0.05\right)$ and $\left(\mathrm{M}_{\text {disso-EW }}=\right.$ 2.414 vs $\mathrm{M}_{\text {disso-EM }}=2.138 ; \mathrm{p}>0.3$ ). Thus, H8b is supported.

The pair comparison T-test showed a significant gender difference in the $\mathrm{C} 2 \mathrm{C}$ effect on product preference. Specifically, women showed a greater positive association with the in-group than did men $\left(\mathrm{M}_{\mathrm{F} \text {-in-grp-pref }}=4.96, \mathrm{M}_{\mathrm{M} \text {-in-grp-pref }}=4.07\right.$, $\mathrm{p}<0.004)$, thus supporting H9a. By contrast, men showed a greater negative association with the out-group and the dissociative group than did women, $\left(\mathrm{M}_{\mathrm{F}-\text { outgrp-pref }}=3.93, \mathrm{M}_{\mathrm{M} \text {-outgrp-pref }}=3.11, \mathrm{p}<0.02\right),\left(\mathrm{M}_{\mathrm{F}-\text { disso-EW-pref }}=3.30\right.$, $\left.\mathrm{M}_{\mathrm{M} \text {-disso-EW-pref }}=2.26, \mathrm{p}<0.001\right)$, and $\left(\mathrm{M}_{\mathrm{F} \text {-disso-EM-pref }}=2.33, \mathrm{M}_{\mathrm{M} \text {-disso-EM-pref }}=2.11, \mathrm{p}\right.$ $<0.4)$. Thus, H9b is supported, except in the case of the extreme negative group (i.e., elderly men), the effect of which was marginal between genders.

To understand the difference between product preference in control vs treatment condition, a pair comparison T-test was performed, which revealed a significant increase in the in-group condition in the case of women $\left(\mathrm{M}_{\mathrm{F} \text {-Treat-in-grp-pref }}\right.$ $=4.92, \mathrm{M}_{\mathrm{F} \text {-Control-in-grp-pref }}=3.92, \mathrm{p}<0.006$ ), thus supporting H6. In the case of the out-group condition, there was marginal negative effect of the out-group on females' product preference $\left(\mathrm{M}_{\mathrm{F} \text {-Treat-out-grp-pref }}=3.92, \mathrm{M}_{\mathrm{F}-\text { Control-out-grp-pref }}=4.23, \mathrm{p}<\right.$ 0.3 ) thus partially supporting $\mathrm{H} 7$; however, there was a significant decrease in the females' product preference in the case of dissociative-groups $\left(\mathrm{M}_{\mathrm{F}-\text { Treat-disso-EW-pref }}=3.35, \mathrm{M}_{\mathrm{F}-\text { Control-disso-EW-pref }}=3.96, \mathrm{p}<0.03\right)\left(\mathrm{M}_{\mathrm{F}-\text { Treat-disso-EM-pref }}=\right.$ $\left.2.35, \mathrm{M}_{\mathrm{F}-\text { Control-disso-EM-pref }}=3.85, \mathrm{p}<0.001\right)$, thus supporting $\mathrm{H} 7$. 
In the case of men, there was a marginal significance in the increase in product preference in the in-group condition $\left(\mathrm{M}_{\mathrm{M} \text {-Treat-in-grp-pref }}=4.12, \mathrm{M}_{\mathrm{M} \text {-Control-in-grp-pref }}\right.$ $=3.72, \mathrm{p}>0.1)$, thus supporting H6. The negative effect was also significant for all three levels, $\left(\mathrm{M}_{\mathrm{M} \text {-Treat-out-grp-pref }}=2.96, \mathrm{M}_{\mathrm{M} \text {-Control-out-grp-pref }}=4.00, \mathrm{p}<0.007\right)$, $\left(\mathrm{M}_{\mathrm{M}-\text { Treat-disso-EW-pref }}=2.24, \quad \mathrm{M}_{\mathrm{M} \text {-Control-disso-EW-pref }}=3.92, \mathrm{p}<0.001\right)$, and $\left(\mathrm{M}_{\mathrm{M}-\text { Treat-disso-EM-pref }}=2.08, \mathrm{M}_{\mathrm{M} \text {-Control-disso-EM-pref }}=3.88, \mathrm{p}<0.0001\right)$, thus supporting H7.

\section{c) Control categorization}

A 2 (gender: female vs male) $\times 4$ (group category: girl, boy, elderly women, elderly men) repeated measures ANOVA was conducted to study the gender effect on categorization. Greenhouse-Geisser correction determined significant effect of group categories $(\mathrm{F}(2.553,125.098)=56.108, \mathrm{p}<0.001)$. There was significant main effect of gender on categorization, $(\mathrm{F}(1,49)=15.989, \mathrm{p}<0.001)$. Post hoc tests using the Bonferroni correction revealed statistically significant difference in categorization of in-group and out-group $\left(\mathrm{M}_{\text {in-grp }}=3.953\right.$ vs $\mathrm{M}_{\text {out-grp }}$ $=3.236 ; \mathrm{p}<0.005)$. It supported H1. There was significant difference between categorization of out-group and dissociative group, $\left(\mathrm{M}_{\text {out-grp }}=3.236 \mathrm{vs} \mathrm{M}_{\text {disso-EW }}=\right.$ 2.228; $\mathrm{p}<0.001$ ). It supported H2. By contrast, the difference in categorization of sub-groups within elder people was not significant $\left(\mathrm{M}_{\text {disso-EW }}=2.228 \mathrm{vs}_{\mathrm{dis}-}\right.$ so-EM $=2.077 ; \mathrm{p}>0.09$ ).

To understand the gender effect, we performed a separate repeated measures ANOVA for the male and female participants. In case of female participants, Greenhouse-Geisser correction determined significant effect of group category, $(\mathrm{F}(2.333,58.330)=43.649, \mathrm{p}<0.0001)$. Post hoc tests using the Bonferroni correction revealed statistically significant difference in categorization of all four groups, $\left(\mathrm{M}_{\mathrm{F} \text {-control-in-grp }}=4.346\right.$ vs $\left.\mathrm{M}_{\mathrm{F}-\text { control-out-grp }}=3.538 ; \mathrm{p}<0.007\right),\left(\mathrm{M}_{\mathrm{F} \text {-control-out-grp }}\right.$ $=3.538$ vs $\left.\mathrm{M}_{\mathrm{F}-\text { control-disso-EW }}=2.577 ; \mathrm{p}<0.003\right)$ and $\left(\mathrm{M}_{\mathrm{F} \text {-control-disso- } \mathrm{EW}}=2.577\right.$ vs $\left.\mathrm{M}_{\mathrm{F} \text {-control-disso-EM }}=2.167 ; \mathrm{p}<0.03\right)$. It has supported H3.

In case of male participants, Greenhouse-Geisser correction determined significant effect of group category, $(\mathrm{F}(1.899,53.169)=30.854, \mathrm{p}<0.001)$. Post hoc tests using the Bonferroni correction revealed statistically significant difference in categorization of large groups (i.e. age groups), $\left(\mathrm{M}_{\mathrm{M} \text {-control-out-grp }}=3.080 \mathrm{vs}\right.$ $\left.\mathrm{M}_{\mathrm{M} \text {-control-disso-EW }}=1.839 ; \mathrm{p}<0.001\right)$. By contrast, there was no significant difference between sub-groups i.e. gender group within age groups, $\left(\mathrm{M}_{\mathrm{M} \text {-control-in-grp }}=\right.$ 3.747 vs $\left.\mathrm{M}_{\mathrm{M} \text {-control-out-grp }}=3.080 ; \mathrm{p}>0.2\right)$, and $\left(\mathrm{M}_{\mathrm{M} \text {-control-disso-EW }}=1.839\right.$ vs $\mathrm{MM}_{\text {-control-disso-EM }}=1.954 ; \mathrm{p}>0.9$ ). It has supported H3.

d) Treatment categorization

A 2 (gender: female vs male) $\times 4$ (group category: girl, boy, elderly women, elderly men) repeated measures ANOVA was conducted to study the gender effect on categorization. Greenhouse-Geisser correction determined significant effect of group categories $(\mathrm{F}(2.264,122.281)=95.078, \mathrm{p}<0.001)$. There was significant main effect of gender on categorization, $(\mathrm{F}(1,54)=7.039, \mathrm{p}<0.02)$. Post hoc tests using the Bonferroni correction revealed statistically significant 
difference in categorization of in-group and out-group $\left(\mathrm{M}_{\text {in-grp }}=4.114\right.$ vs $\mathrm{M}_{\text {out-grp }}$ $=3.411 ; \mathrm{p}<0.001)$. It supported H1. There was significant difference between categorization of out-group and dissociative group, $\left(\mathrm{M}_{\text {out-grp }}=3.411 \mathrm{vs} \mathrm{M}_{\text {disso-Ew }}=\right.$ $2.160 ; \mathrm{p}<0.001)$. It supported H2. By contrast, the difference in categorization of sub-groups within old-age group was marginally significant. $\left(\mathrm{M}_{\text {disso-EW }}=2.160\right.$ vs $\left.\mathrm{M}_{\text {disso-EM }}=1.940 ; \mathrm{p}<0.07\right)$.

Further, the separate repeated measures ANOVAs were performed for the male and female participants.

The Mauchly's test of sphericity, in case of female participants indicated that the assumption of sphericity is not violated, $\chi^{2}(5)=5.726, p>0.4$ and the sphericity assumed results showed significant main effect of group category, ( $F$ (3, $78)=81.183, \mathrm{p}<0.001$. Further, post hoc tests using the Bonferroni correction revealed that there was statistically significant difference in categorization of all four groups, $\left(\mathrm{M}_{\mathrm{F}-\text { in-grp }}=4.481\right.$ vs $\left.\mathrm{M}_{\mathrm{F} \text {-out-grp }}=3.741 ; \mathrm{p}<0.02\right) ;\left(\mathrm{M}_{\mathrm{F} \text {-out-grp }}=3.741\right.$ vs $\left.\mathrm{M}_{\mathrm{F}-\mathrm{disso}-\mathrm{EW}}=2.481 ; \mathrm{p}<0.002\right) ;$ and $\left(\mathrm{M}_{\mathrm{F}-\text { disso-EW }}=2.481\right.$ vs $\mathrm{M}_{\mathrm{F} \text {-disso-EM }}=1.926 ; \mathrm{p}<$ 0.007), which supported $\mathrm{H} 3$.

In case of men participants, Greenhouse-Geisser correction determined significant effect of group categories $(\mathrm{F}(1.899,53.169)=30.854, \mathrm{p}<0.001)$. As predicted, Post hoc tests using the Bonferroni correction revealed statistically significant difference in categorization of large groups i.e. age groups, $\left(\mathrm{M}_{\mathrm{M} \text {-Treat-out-grp }}\right.$ $=3.080$ vs $\left.\mathrm{M}_{\mathrm{M} \text {-Treat-disso-EW }}=1.839 ; \mathrm{p}<0.001\right)$. Whereas, the difference between categorization of subgroups (gender) within each age group was not significant, $\left(\mathrm{M}_{\mathrm{M} \text {-Treat-disso-EW }}=1.839\right.$ vs $\left.\mathrm{M}_{\mathrm{M} \text {-Treat-disso-EM }}=1.954 ; \mathrm{p}>0.9\right)$ and $\left(\mathrm{M}_{\mathrm{M} \text {-Treat-in-grp }}=\right.$ 3.747 vs $\mathrm{M}_{\mathrm{M} \text {-Treat-out-grp }}=3.080 ; \mathrm{p}>0.1$ ). This supports, $\mathrm{H} 3$.

\subsubsection{Discussion}

Pretest-1 showed a successful manipulation of the groups based on gender and age. Pretest-2 showed no significant differences among the four product types and that the preferences lie in the medium range. The findings of experiment 1 showed significant difference between the men and the women in the categorization; as predicted, women endorsed more categories than did men, i.e., they clearly distinguished groups based on gender and age, whereas the men endorsed larger groups based on age and the difference in categorization of sub-groups based on gender within age groups was not significant. The women showed a greater positive association with the in-group than did the men, whereas the men showed a greater negative association with the out-group and the dissociative group than did the women. The findings of experiment 2 showed the significant influence of group categorization in $\mathrm{C} 2 \mathrm{C}$ encounter on product preference. As predicted, the in-group had a more positive effect on women's product preference than on men's preference, whereas the out-group and the dissociative group had a more negative influence on men's product preference than women's preference. It also showed the overall greater positive social projection of women towards all groups than of men. 


\section{Conclusion}

Given the intense social imbalance in the modern world, great responsibility lies with all researchers from the fields of psychology, the social sciences and sociology to highlight reality, i.e., the similarities in behavioral patterns, to reduce discrimination based on superficial differences, whether gender- or age-based discrimination or nationality- or community-based discrimination, and the associated social issues that arise from biased social inputs and influences which are the root causes of these orientations. As the consequences are not only limited to pink for girls and blue for boys, they also lead to bias in evaluation of individuals and things associated with them.

\section{Managerial Implications}

It is important to pay attention to group biases because they are often unfair and unjustifiable, as they go beyond objective requirements [111] and, thus, prevent rational judgments. The gender bias and ageism are the worldwide social issues and is reported in social psychological researches conducted worldwide. The findings of a worldwide study conducted by Nosek et al. [97] found that gender inequality was significant in all nations under study. Similarly, gender stereotyping was reported among people of all ages and professions in academia, e.g., undergraduate women [65] and male and female faculty [93]. These beliefs are widely shared by women and men and are present in all cultures studied to date [33] [112] [113]. As gender and age stereotypes are the most common, significant, stable, readily available and the most frequently used stereotypes, present in all cultures, nations, ages and professions, the findings of our study are widely applicable. It also makes a priority to pay attention to this process in every managerial field where human behavior plays key role in organizational success including management, psychology, social sciences, human resource as well as academics and encourages them to help people to effectively overcome the gender bias and ageism in the family, academics, employment as well as in the social and business environment and help people in making their thinking, decision making and behavior rational.

Our findings suggest that the difference in the categorization and degree of association with groups based on gender and age also significantly affects the preference for products in a $\mathrm{C} 2 \mathrm{C}$ encounter. This study is the first to simultaneously investigate the difference in the negative influence of the out-group and the dissociative group. The findings regarding the triadic gender effect in a $\mathrm{C} 2 \mathrm{C}$ encounter on product preference will help the product and service industry to encourage positive encounters by offering group memberships or by minimizing negative influences. In internet shopping, the virtual $\mathrm{C} 2 \mathrm{C}$ encounter is possible when consumers post feedbacks, queries or comment on websites; in advertising, the virtual $\mathrm{C} 2 \mathrm{C}$ encounter occur with the actors in the consumer's role; in promotional events or exhibitions, the $\mathrm{C} 2 \mathrm{C}$ encounters occur with the people present at the promotional events and the findings of this study will help them to 
minimize the negative and facilitate the positive encounter creatively.

Retail businesses, supermarkets or malls should consider the TGE and C2C encounter and should enhance positive encounter by constructing separate sections based on gender and age groups. Recently, several retail brands have opened separate outlets for plus-sized clothes; similarly, a divide-and-conquer strategy might be helpful. FMCG companies should enhance positive C2C encounters by introducing products with specific gender or age tag such as body soaps or perfumes for men or boys or for women or girls. Online stores should create separate web pages for girls, boys, elderly people and kids to facilitate positive in-group effect.

\section{Future Research}

Although, our research is focused on buying behavior but it has also successfully brought up some serious issues of gender discrimination and ageism. The TGE process responsible for gender difference, begins at the early childhood and is created, maintained and nourished through social learning from their close and later from distant social environment. The stereotypes of self and others, thus continue becoming stronger and stronger, and broader and broader over-time. This bias although begins with pink for girls and blue for boys or dolls for girls and guns for boys but later it takes serious forms like discrimination and suppression of the weaker groups which leads to fear, dependence, introvert personality, lack of confidence, social pressure and even depression [107] [114]. The biased social orientation often leads to victimization of lower-status groups which affects their self-concept; for e.g. boys show stronger self-concept associated with math [115] [116], science [115] [116] and engineering [111] than girls and it also affects their performance [25] [31] and carrier decisions [111] [115] and also leads to bias decisions like gender bias against female students by science faculty [117]. As these biases have a severe damaging effect on "global society". Hence, this research suggests the researchers in the field of psychology, academics, social science, and human resource to conduct further research on gender bias and ageism to find out ways to bring gender equality from within to overcome the behavioral bias in the society, worldwide.

It also suggests researchers in the marketing field to conduct further research on the TGE and C2C encounters in different buying scenarios like online shopping, advertising or service industry.

\section{Acknowledgements}

This research is awarded financial aid from Ministry of Education (MOE), Taiwan. I am grateful to MOE for the same. I am grateful to National Science Council of Taiwan and National Taiwan University of Science and Technology. I dedicate this research to my parents Mrs. Sharada S. Kirkole, Mr. Sharad P. Kirkole, as they are the great inspiration for me. I am grateful to my husband Dr. B.V. Bhagwat and brother Mr. Shirish S. Kirkole for their moral support during this research. 


\section{References}

[1] Nelson, T.D. (2005) Ageism: Prejudice against Our Feared Future Self. Journal of Social Issues, 61, 207-221. https://doi.org/10.1111/j.1540-4560.2005.00402.x

[2] Bem, S.L. (1981) Gender Schema Theory: A Cognitive Account of Sex Typing. Psychological Review, 88, 354-364. https://doi.org/10.1037/0033-295X.88.4.354

[3] Martin, C.L. and Halverson, Jr., C.F. (1981) A Schematic Processing Model of Sex Typing and Stereotyping in Children. Child Development, 52, 1119-1134. https://doi.org/10.2307/1129498

[4] Fournier, S. (1998) Consumers and Their Brands: Developing Relationship Theory in Consumer Research. Journal of Consumer Research, 24, 343-353. https://doi.org/10.1086/209515

[5] Bem, S.L. (1981) Gender Schema Theory: A Cognitive Account of Sex Typing. Psychological Review, 88, 354-364. https://doi.org/10.1037/0033-295X.88.4.354

[6] Montford, W. and Goldsmith, R.E. (2016) How Gender and Financial Self-Efficacy Influence Investment Risk Taking. International Journal of Consumer Studies, 40, 101-106. https://doi.org/10.1111/ijcs.12219

[7] Hewstone, M., Rubin, M. and Willis, H. (2002) Intergroup Bias. Annual Review of Psychology, 53, 575-604. https://doi.org/10.1146/annurev.psych.53.100901.135109

[8] Mackie, D.M. and Smith, E.R. (1998) Intergroup Relations: Insights from a Theoretically Integrative Approach. Psychological Review, 105, 499-529.

https://doi.org/10.1037/0033-295X.105.3.499

[9] Wilder, D. and Simon, A. (2001) Affect as a Cause of Intergroup Bias. Blackwell Handbook of Social Psychology: Intergroup Processes, 153-172.

[10] Brewer, M.B. and Brown, R.J. (1998) Intergroup Relations. In: Gilbert, D.T., Fiske, S.T. and Lindzey, G., Eds., The Handbook of Social Psychology, McGraw-Hill, New York, 554-594.

[11] Fiske, S.T. (1998) Stereotyping, Prejudice, and Discrimination. In: Gilbert, D.T., Fiske, S.T. and Lindzey, G., Eds., The Handbook of Social Psychology, Vols. 1 and 2, 4th Edition, McGraw-Hill, New York, 357-411.

[12] Turner, J.C. and Reynolds, K.J. (2001) The Social Identity Perspective in Intergroup Relations: Theories, Themes, and Controversies. In: Browne, R. and Gaertner, S., Eds., Blackwell Handbook of Social Psychology: Intergroup Processes, Wiley-Blackwell, Malden, 133-152.

[13] Weinreich, P. and Saunderson, W. (2003) Analysing Identity. Cross-Cultural, Societal and Clinical Contexts. Routledge, London.

[14] Turner, J.C. (1991) Social Influence. Open University Press, Milton Keynes.

[15] Englis, B.G. and Solomon, M.R. (1995) To Be and Not to Be: Lifestyle Imagery, Reference Groups, and the Clustering of America. Journal of Advertising, 24, 13-28. https://doi.org/10.1080/00913367.1995.10673465

[16] Markus, H. and Nurius, P. (1986) Possible Selves. American Psychologist, 41, 954-969. https://doi.org/10.1037/0003-066X.41.9.954

[17] Ogilvie, D.M. (1987) The Undesired Self: A Neglected Variable in Personality Research. Journal of Personality and Social Psychology, 52, 379-385.

https://doi.org/10.1037/0022-3514.52.2.379

[18] Brewer, M.B. (1979) In-Group Bias in the Minimal Intergroup Situation: A Cognitive-Motivational Analysis. Psychological Bulletin, 86, 307-324.

https://doi.org/10.1037/0033-2909.86.2.307 
[19] Marques, J., Abrams, D., Paez, D. and Martinez-Taboada, C. (1998) The Role of Categorization and In-Group Norms in Judgments of Groups and Their Members. Journal of Personality and Social Psychology, 75, 976-988. https://doi.org/10.1037/0022-3514.75.4.976

[20] White, K. and Dahl, D.W. (2007) Are All Out-Groups Created Equal? Consumer Identity and Dissociative Influence. Journal of Consumer Research, 34, 525-536. https://doi.org/10.1086/520077

[21] Butler, R.N. (1969) Age-Ism: Another Form of Bigotry. The Gerontologist, 9, 243-246. https://doi.org/10.1093/geront/9.4_Part_1.243

[22] Wilkinson, J.A. and Ferraro, K.F. (2002) Thirty Years of Ageism Research. In: Nelson, T.D., Ed., Ageism: Stereotyping and Prejudice against Older Persons, MIT Press, Cambridge.

[23] Perdue, C.W. and Gurtman, M.B. (1990) Evidence for the Automaticity of Ageism. Journal of Experimental Social Psychology, 26, 199-216. https://doi.org/10.1016/0022-1031(90)90035-K

[24] Triandis, H.C. (1989) The Self and Social Behavior in Differing Cultural Contexts. Psychological Review, 96, 506-520. https://doi.org/10.1037/0033-295X.96.3.506

[25] Markus, H. and Kitayama, S. (1991) Culture and the Self: Implications for Cognition, Emotion, and Motivation. Psychological Review, 98, 224-253. https://doi.org/10.1037/0033-295X.98.2.224

[26] Brewer, M.B. and Gardner, W. (1996) Who Is This "We"? Levels of Collective Identity and Self-Representations. Journal of Personality and Social Psychology, 71, 83-93. https://doi.org/10.1037/0022-3514.71.1.83

[27] Fiske, S.T. and Taylor, S.E. (1991) Social Cognition. 2nd Edition, McGraw-Hill, New York.

[28] Kihlstrom, J.F. and Klein, S.B. (1994) The Self as a Knowledge Structure. In: Wyerand, R.S. and Srull, T.K., Eds., Handbook of Social Cognition: Applications, L. Erlbaum Associates, Hillsdale, 153-208.

[29] Dunning, D. and Hayes, A.F. (1996) Evidence for Egocentric Comparison in Social Judgment. Journal of Personality and Social Psychology, 71, 213-229.

https://doi.org/10.1037/0022-3514.71.2.213

[30] Cross, S.E. and Madson, L. (1997) Models of the Self: Self-Construals and Gender. Psychological Bulletin, 122, 5-37. https://doi.org/10.1037/0033-2909.122.1.5

[31] Biernat, M., Vescio, T.K. and Green, M.L. (1996) Selective Self-Stereotyping. Journal of Personality and Social Psychology, 71, 1194-1209.

https://doi.org/10.1037/0022-3514.71.6.1194

[32] Doosje, B. and Ellemers, N. (1997) Stereotyping under Threat: The Role of Group Identification. In: Spears, R., Oakes, P.J., Ellemersand, N. and Haslam, S.A., Eds., The Social Psychology of Stereotyping and Group Life, Wiley, Oxford, 257-272.

[33] Spears, R., Doosje, B. and Ellemers, N. (1997) Self-Stereotyping in the Face of Threats to Group Status and Distinctiveness: The Role of Group Identification. Personality and Social Psychology Bulletin, 23, 538-553. https://doi.org/10.1177/0146167297235009

[34] Biernat, M., Crandall, C.S., Young, L.V., Kobrynowicz, D. and Halpin, S.M. (1998) All That You Can Be: Stereotyping of Self and Others in a Military Context. Journal of Personality and Social Psychology, 75, 301-317. https://doi.org/10.1037/0022-3514.75.2.301

[35] Pickett, C.L., Bonner, B.L. and Coleman, J.M. (2002) Motivated Self-Stereotyping: 
Heightened Assimilation and Differentiation Needs Result in Increased Levels of Positive and Negative Self-Stereotyping. Journal of Personality and Social Psychology, 82, 543-562. https://doi.org/10.1037/0022-3514.82.4.543

[36] Onorato, R.S. and Turner, J.C. (2004) Fluidity in the Self-Concept: The Shift from Personal to Social Identity. European Journal of Social Psychology, 34, 257-278. https://doi.org/10.1002/ejsp.195

[37] Gabriel, S. and Gardner, W.L. (1999) Are There "His" and "Hers" Types of Interdependence? The Implications of Gender Differences in Collective versus Relational Interdependence for Affect, Behavior, and Cognition. Journal of Personality and Social Psychology, 77, 642-655. https://doi.org/10.1037/0022-3514.77.3.642

[38] Cross, S.E., Bacon, P.L. and Morris, M.L. (2000) The Relational-Interdependent Self-Construal and Relationships. Journal of Personality and Social Psychology, 78, 791-808. https://doi.org/10.1037/0022-3514.78.4.791

[39] Kemmelmeier, M. and Oyserman, D. (2001) The Ups and Downs of Thinking about a Successful Other: Self-Construals and the Consequences of Social Comparisons. European Journal of Social Psychology, 31, 311-320. https://doi.org/10.1002/ejsp.47

[40] Gardner, W.L., Gabriel, S. and Hochschild, L. (2002) When You and I Are "We," You Are Not Threatening: The Role of Self-Expansion in Social Comparison. Journal of Personality and Social Psychology, 82, 239-251.

https://doi.org/10.1037/0022-3514.82.2.239

[41] Kashima, Y., Kokubo, T., Kashima, E.S., Boxall, D., Yamaguchi, S. and Macrae, K. (2004) Culture and Self: Are There Within-Culture Differences in Self between Metropolitan Areas and Regional Cities? Personality and Social Psychology Bulletin, 30, 816-823. https://doi.org/10.1177/0146167203261997

[42] Cross, S.E., Morris, M.L. and Gore, J.S. (2002) Thinking about Oneself and Others: The Relational-Interdependent Self-Construal and Social Cognition. Journal of Personality and Social Psychology, 82, 399-418. https://doi.org/10.1037/0022-3514.82.3.399

[43] Maddux, W.W. and Brewer, M.B. (2005) Gender Differences in the Relational and Collective Bases for Trust. Group Processes and Intergroup Relations, 8, 159-171. https://doi.org/10.1177/1368430205051065

[44] Markus, H. and Kitayama, S. (1994) A Collective Fear of the Collective: Implications for Selves and Theories of Selves. Personality \& Social Psychology Bulletin, 20, 568-579. https://doi.org/10.1177/0146167294205013

[45] Weisz, J.R., Rothbaum, F.M. and Blackburn, T.C. (1984) Standing Out and Standing In: The Psychology of Control in America and Japan. American Psychologist, 39, 955-969. https://doi.org/10.1037/0003-066X.39.9.955

[46] Tesser, A. (1988) Toward a Self-Evaluation Maintenance Model of Social Behavior. In: Berkowitz, L., Ed., Advances in Experimental Social Psychology, Academic Press, New York, 21. https://doi.org/10.1016/S0065-2601(08)60227-0

[47] Maccoby, E.E. (1990) Gender and Relationships: A Developmental Account. American Psychologist, 45, 513-520. https://doi.org/10.1037/0003-066X.45.4.513

[48] Markus, H. and Cross, S. (1990) The Interpersonal Self. In: Pervin, L.A., Ed., Handbook of Personality Theory and Research, Guilford, New York, 576-608.

[49] Aaker, J. and Schmitt, B. (2001) Culture-Dependent Assimilation and Differentiation of the Self: Preferences for Consumption Symbols in the United States and China. Journal of Cross-Cultural Psychology, 32, 561-576.

https://doi.org/10.1177/0022022101032005003 
[50] Kampmeier, C. and Simon, B. (2001) Individuality and Group Formation: The Role of Independence and Differentiation. Journal of Personality and Social Psychology, 81, 448-462. https://doi.org/10.1037/0022-3514.81.3.448

[51] Ickes, W., Robertson, E., Tooke, W. and Teng, G. (1986) Naturalistic Social Cognition: Methodology, Assessment, and Validation. Journal of Personality and Social Psychology, 51, 66-82. https://doi.org/10.1037/0022-3514.51.1.66

[52] Clancy, S.M. and Dollinger, S.J. (1993) Photographic Depictions of the Self: Gender and Age Differences in Social Connectedness. Sex Roles, 29, 477-495. https://doi.org/10.1007/BF00289322

[53] Bakan, D. (1966) The Duality of Human Existence: Isolation and Communion in Western Man. Beacon Press, Boston.

[54] Haas, A. (1979) Male and Female Spoken Language Differences: Stereotypes and Evidence. Psychological Bulletin, 86, 616-626. https://doi.org/10.1037/0033-2909.86.3.616

[55] Meyers-Levy, J. (1988) The Influence of Sex Roles on Judgment. Journal of Consumer Research, 14, 522-530. https://doi.org/10.1086/209133

[56] Costa, Jr., P., Terracciano, A. and McCrae, R.R. (2001) Gender Differences in Personality Traits across Cultures: Robust and Surprising Findings. Journal of Personality and Social Psychology, 81, 322-331. https://doi.org/10.1037/0022-3514.81.2.322

[57] Pearsall, N.R., Skipper, J.E.J. and Mintzes, J.J. (1997) Knowledge Restructuring in the Life Sciences: A Longitudinal Study of Conceptual Change in Biology. Science Education, 81, 193-215. https://doi.org/10.1002/(SICI)1098-237X(199704)81:2<193::AID-SCE5>3.0.CO;2-A

[58] Benyamini, Y., Leventhal, E.A. and Leventhal, H. (2000) Gender Differences in Processing Information for Making Self-Assessments of Health. Psychosomatic Medicine, 62, 354-364. https://doi.org/10.1097/00006842-200005000-00009

[59] Laroche, M., Saad, G., Cleveland, M. and Browne, E. (2000) Gender Differences in Information Search Strategies for a Christmas Gift. Journal of Consumer Marketing, 17, 500-522. https://doi.org/10.1108/07363760010349920

[60] Voss, J.F. and Van Dyke, J.A. (2001) Narrative Structure, Information Certainty, Emotional Content, and Gender as Factors in a Pseudo Jury Decision-Making Task. Discourse Processes, 32, 215-243. https://doi.org/10.1080/0163853X.2001.9651599

[61] Laroche, M., Cleveland, M., Bergeron, J. and Goutaland, C. (2003) The Knowledge-Experience-Evaluation Relationship: A Structural Equations Modeling Test of Gender Differences. Canadian Journal of Administrative Sciences, 20, 246-259. https://doi.org/10.1111/j.1936-4490.2003.tb00315.x

[62] Signorella, M.L., Bigler, R.S. and Liben, L.S. (1993) Developmental Differences in Children's Gender Schemata about Others: A Meta-Analytic Review. Developmental Review, 13, 147-183. https://doi.org/10.1006/drev.1993.1007

[63] O’Brien, M., Peyton, V., Mistry, R., Hruda, L., Jacobs, A., Caldera, Y., Huston, A. and Roy, C. (2000) Gender-Role Cognition in Three-Year-Old Boys and Girls. Sex Roles, 42, 1007-1025. https://doi.org/10.1023/A:1007036600980

[64] Serbin, L.A., Poulin-Dubois, D., Colburne, K.A., Sen, M.G. and Eichstedt, J.A. (2001) Gender Stereotyping in Infancy: Visual Preferences for and Knowledge of Gender-Stereotyped Toys in the Second Year. International Journal of Behavioral Development, 25, 7-15. https://doi.org/10.1080/01650250042000078

[65] Miller, C.F., Lurye, L.E., Zosuls, K.M. and Ruble, D.N. (2009) Accessibility of 
Gender Stereotype Domains: Developmental and Gender Differences in Children. Sex Roles, 60, 870-881. https://doi.org/10.1007/s11199-009-9584-x

[66] Popcorn, F. and Marigold, L. (2000) Buy This Bear to Become Popular and Trendy. In: Evolution: The Eight Truths of Marketing to Women, Hyperion, New York.

[67] Fisher, H.E. (1999) The First Sex: The Natural Talents of Women and How They Are Changing the World. Random House, New York.

[68] Holbrook, M.B. (1986) The Role of Emotion in the Consumption Experience: Actions and Reactions in Consumer Behavior. In: Lutz, R.J., Ed., NA-Advances in Consumer Research, Association for Consumer Research, Provo, 13,666.

[69] Bleich, D. (1988) Gender Interests in Reading and Language. In: Flynn and Schweickart, Eds., Gender and Reading. Essays on Readers, Texts, and Contexts, Johns Hopkins University Press, Baltimore, 234-266.

[70] Forster, J., Liberman, N. and Kuschel, S. (2008) The Effect of Global versus Local Processing Styles on Assimilation versus Contrast in Social Judgment. Journal of Personality and Social Psychology, 94, 579-599. https://doi.org/10.1037/0022-3514.94.4.579

[71] Friedman, R.S. and Forster, J. (2000) The Effects of Approach and Avoidance Motor Actions on the Elements of Creative Insight. Journal of Personality and Social Psychology, 79, 477-492. https://doi.org/10.1037/0022-3514.79.4.477

[72] Forster, J. and Higgins, E.T. (2005) How Global versus Local Perception Fits Regulatory Focus. Psychological Science, 16, 631-636. https://doi.org/10.1111/j.1467-9280.2005.01586.x

[73] Forster, J., Friedman, R.S., Özelsel, A. and Denzler, M. (2006) Enactment of Approach and Avoidance Behavior Influences the Scope of Perceptual and Conceptual Attention. Journal of Experimental Social Psychology, 42, 133-146. https://doi.org/10.1016/j.jesp.2005.02.004

[74] Nussinson, R., Häfner, M., Seibt, B., Strack, F. and Trope, Y. (2012) Approach/Avoidance Orientations Affect Self-Construal and Identification with In-Group. Self and Identity, 11, 255-272. https://doi.org/10.1080/15298868.2011.559044

[75] Lee, A.Y., Aaker, J.L. and Gardner, W.L. (2000) The Pleasures and Pains of Distinct Self-Construals: The Role of Interdependence in Regulatory Focus. Journal of Personality and Social Psychology, 78, 1122-1134. https://doi.org/10.1037/0022-3514.78.6.1122

[76] Aaker, J.L. and Lee, A.Y. (2001) "I" Seek Pleasures and "We" Avoid Pains: The Role of Self-Regulatory Goals in Information Processing and Persuasion. Journal of Consumer Research, 28, 33-49. https://doi.org/10.1086/321946

[77] Robbins, J.M. and Krueger, J.I. (2005) Social Projection to Ingroups and Outgroups: A Review and Meta-Analysis. Personality and Social Psychology Review, 9, 32-47. https://doi.org/10.1207/s15327957pspr0901_3

[78] Baumeister, R.F. and Sommer, K.L. (1997) What Do Men Want? Gender Differences and Two Spheres of Belongingness: Comment on Cross and Madson. Psychological Bulletin, 122, 38-44. https://doi.org/10.1037/0033-2909.122.1.38

[79] Arndt, J., Greenberg, J., Solomon, S., Pyszczynski, T. and Schimel, J. (1999) Creativity and Terror Management: Evidence That Creative Activity Increases Guilt and Social Projection Following Mortality Salience. Journal of Personality and Social Psychology, 77, 19-32. https://doi.org/10.1037/0022-3514.77.1.19

[80] Fiske, S.T., Cuddy, A.J., Glick, P. and Xu, J. (2002) A Model of (Often Mixed) Ste- 
reotype Content: Competence and Warmth Respectively Follow from Perceived Status and Competition. Journal of Personality and Social Psychology, 82, 878-902. https://doi.org/10.1037/0022-3514.82.6.878

[81] Fiske, S.T. and Cuddy, A.J. (2006) Stereotype Content and Relative Group Status across Cultures. In: Guimond, S., Ed., Social Comparison and Social Psychology: Understanding Cognition, Intergroup Relations, and Culture, Cambridge University Press, 249-263.

[82] Helgeson, V.S. (1994) Relation of Agency and Communion to well-Being: Evidence and Potential Explanations. Psychological Bulletin, 116, 412-428. https://doi.org/10.1037/0033-2909.116.3.412

[83] Moskowitz, D.S., Suh, E.J. and Desaulniers, J. (1994) Situational Influences on Gender Differences in Agency and Communion. Journal of Personality and Social Psychology, 66, 753-761. https://doi.org/10.1037/0022-3514.66.4.753

[84] Sidanius, J., Pratto, F. and Bobo, L. (1994) Social Dominance Orientation and the Political Psychology of Gender: A Case of Invariance? Journal of Personality and Social Psychology, 67, 998. https://doi.org/10.1037/0022-3514.67.6.998

[85] Wood, W., Christensen, P.N., Hebl, M.R. and Rothgerber, H. (1997) Conformity to Sex-Typed Norms, Affect, and the Self-Concept. Journal of Personality and Social Psychology, 73, 523-535. https://doi.org/10.1037/0022-3514.73.3.523

[86] Glick, P. and Fiske, S.T. (2001) An Ambivalent Alliance: Hostile and Benevolent Sexism as Complementary Justifications for Gender Inequality. American Psychologist, 56, 109-118. https://doi.org/10.1037/0003-066X.56.2.109

[87] Turner, J.C. (1987) Rediscovering the Social Group: A Self-Categorization Theory. B. Blackwell, Oxford and New York.

[88] Rudman, L.A. and Goodwin, S.A. (2004) Gender Differences in Automatic In-Group Bias: Why Do Women like Women More than Men like Men? Journal of Personality and Social Psychology, 87, 494-509. https://doi.org/10.1037/0022-3514.87.4.494

[89] Fournier, M.A. (2002) Agency and Communion as Fundamental Dimensions of Social Adaptation and Emotional Adjustment. Doctoral Thesis, McGill University.

[90] Nosek, B.A., Banaji, M.R. and Greenwald, A.G. (2002) Math = Male, Me = Female, Therefore Math Not = Me. Journal of Personality and Social Psychology, 83, 44-59. https://doi.org/10.1037/0022-3514.83.1.44

[91] Richeson, J.A. and Ambady, N. (2001) Who's in Charge? Effects of Situational Roles on Automatic Gender Bias. Sex Roles, 44, 493-512. https://doi.org/10.1023/A:1012242123824

[92] McDonald, P., Pini, B., Bailey, J. and Price, R. (2011) Young People's Aspirations for Education, Work, Family and Leisure. Work, Employment and Society, 25, 68-84. https://doi.org/10.1177/0950017010389242

[93] Locke, K.D. and Nekich, J.C. (2000) Agency and Communion in Naturalistic Social Comparison. Personality and Social Psychology Bulletin, 26, 864-874. https://doi.org/10.1177/0146167200269011

[94] Bearden, W.O. and Etzel, M.J. (1982) Reference Group Influence on Product and Brand Purchase Decisions. Journal of Consumer Research, 9, 183-194. https://doi.org/10.1086/208911

[95] Moschis, G.P. (1985) The Role of Family Communication in Consumer Socialization of Children and Adolescents. Journal of Consumer Research, 11, 898-913. https://doi.org/10.1086/209025 
[96] Bearden, W.O., Netemeyer, R.G. and Teel, J.E. (1989) Measurement of Consumer Susceptibility to Interpersonal Influence. Journal of Consumer Research, 15, 473-481. https://doi.org/10.1086/209186

[97] Childers, T.L. and Rao, A.R. (1992) The Influence of Familial and Peer-Based Reference Groups on Consumer Decisions. Journal of Consumer Research, 19, 198-211. https://doi.org/10.1086/209296

[98] Escalas, J.E. and Bettman, J.R. (2003) You Are What They Eat: The Influence of Reference Groups on Consumers' Connections to Brands. Journal of Consumer Psychology, 13, 339-348. https://doi.org/10.1207/S15327663JCP1303_14

[99] Belk, R.W. (1988) Possessions and the Extended Self. Journal of Consumer Research, 15, 139-168. https://doi.org/10.1086/209154

[100] Richins, M.L. (1994) Special Possessions and the Expression of Material Values. Journal of Consumer Research, 21, 522-533. https://doi.org/10.1086/209415

[101] Escalas, J.E. and Bettman, J.R. (2005) Self-Construal, Reference Groups, and Brand Meaning. Journal of Consumer Research, 32, 378-389.

https://doi.org/10.1086/497549

[102] Whittler, T.E. and Spira, J.S. (2002) Model's Race: A Peripheral Cue in Advertising Messages? Journal of Consumer Psychology, 12, 291-301. https://doi.org/10.1016/S1057-7408(16)30081-X

[103] Terry, D.J. and Hogg, M.A. (1996) Group Norms and the Attitude-Behavior Relationship: A Role for Group Identification. Personality and Social Psychology Bulletin, 22, 776-793. https://doi.org/10.1177/0146167296228002

[104] Park, C.W. and Lessig, V.P. (1977) Students and Housewives: Differences in Susceptibility to Reference Group Influence. Journal of Consumer Research, 4, 102-110. https://doi.org/10.1086/208685

[105] Moschis, G.P. (1976) Social Comparison and Informal Group Influence. Journal of Marketing Research, 13, 237-244. https://doi.org/10.2307/3150733

[106] Madrigal, R. (2000) The Role of Corporate Associations in New Product Evaluation. In: Hoch, S.J. and Meyer, R.J., Eds., Advances in Consumer Research, Vol. 27, Association for Consumer Research, Provo, 80-86.

[107] Banister, E.N. and Hogg, M.K. (2004) Negative Symbolic Consumption and Consumers' Drive for Self-Esteem: The Case of the Fashion Industry. European Journal of Marketing, 38, 850-868. https://doi.org/10.1108/03090560410539285

[108] Lowrey, T.M., Englis, B.G., Shavitt, S. and Solomon, M.R. (2001) Response Latency Verification of Consumption Constellations: Implications for Advertising Strategy. Journal of Advertising, 30, 29-39. https://doi.org/10.1080/00913367.2001.10673629

[109] Muniz, A.M. and Hamer, L.O. (2001) Us versus Them: Oppositional Brand Loyalty and the Cola Wars. Advances in Consumer Research, 28, 355-361.

[110] White, K. and Argo, J.J. (2009) Social Identity Threat and Consumer Preferences. Journal of Consumer Psychology, 19, 313-325. https://doi.org/10.1016/j.jcps.2009.03.007

[111] Correll, S.J. (2001) Gender and the Career Choice Process: The Role of Biased Self-Assessments. American Journal of Sociology, 106, 1691-1730. https://doi.org/10.1086/321299

[112] Williams, J.E. and Best, D.L. (1986) Sex Stereotypes and Intergroup Relations. In: Austin, W.G. and Worchel, S., Eds., Psychology of Intergroup Relations, Nelson-Hall Publishers, Chicago, 244-259.

[113] Nosek, B.A., Smyth, F.L., Sriram, N., Lindner, N.M., Devos, T., Ayala, A., Bar-Anan, 
Y., Bergh, R., Cai, H., Gonsalkorale, K., Kesebir, S., Maliszewski, N., Neto, F., Olli, E., Park, J., Schnabel, K., Shiomura, K., Tulbure, B.T., Wiers, R.W. and Somogyi, M. (2009) National Differences in Gender-Science Stereotypes Predict National Sex Differences in Science and Math Achievement. Proceedings of the National Academy of Sciences of the United States of America, 106, 10593-10597.

https://doi.org/10.1073/pnas.0809921106

[114] Platt, J., Prins, S., Bates, L. and Keyes, K. (2016) Unequal Depression for Equal Work? How the Wage Gap Explains Gendered Disparities in Mood Disorders. Social Science \& Medicine, 149, 1-8. https://doi.org/10.1016/j.socscimed.2015.11.056

[115] Kiefer, A.K. and Sekaquaptewa, D. (2007) Implicit Stereotypes, Gender Identification, and Math-Related Outcomes a Prospective Study of female College Students. Psychological Science, 18, 13-18. https://doi.org/10.1111/j.1467-9280.2007.01841.x

[116] Cvencek, D., Meltzoff, A.N. and Greenwald, A.G. (2011) Math-Gender Stereotypes in Elementary School Children. Child Development, 82, 766-779.

https://doi.org/10.1111/j.1467-8624.2010.01529.x

[117] Moss-Racusin, C.A., Dovidio, J.F., Brescoll, V.L., Graham, M.J. and Handelsman, J. (2012) Science Faculty's Subtle Gender Biases Favor Male Students. Proceedings of the National Academy of Sciences of the United States of America, 109, 16474-16479. https://doi.org/10.1073/pnas.1211286109 